\title{
XIAP-associating factor 1, a transcriptional target of BRD7, contributes to endothelial cell senescence
}

\author{
Jong-Ik Heo ${ }^{1}$, Wonwoo $\mathrm{Kim}^{2}$, Kyu Jin $\mathrm{Choi}^{1}$, Sangwoo Bae ${ }^{1}$, Jae-Hoon Jeong ${ }^{2}$ and \\ Kwang Seok Kim ${ }^{1}$ \\ ${ }^{1}$ Divisions of Radiation Effects, Korea Institute of Radiological and Medical Sciences, Seoul, Republic of Korea \\ 2 Research Center for Radiotherapy, Korea Institute of Radiological and Medical Sciences, Seoul, Republic of Korea \\ Correspondence to: Kwang Seok Kim, email: kskim@kirams.re.kr \\ Keywords: XAF1, p53, ionizing radiation, DNA damage, cellular senescence, BRD7, Gerotarget \\ Received: September 09, 2015 Accepted: January 15, 2016 \\ Published: January 20, 2016
}

\section{ABSTRACT}

X-linked inhibitor of apoptosis (XIAP)-associated factor 1 (XAF1) is well known as an antagonist of XIAP-mediated caspase inhibition. Although XAF1 serves as a tumor-suppressor gene, the role of XAF1 in cellular senescence remains unclear. We found that XAF1 expression was increased by genotoxic agents, such as doxorubicin and ionizing radiation in pulmonary microvascular endothelial cells, consequently leading to premature senescence. Conversely, downregulation of XAF1 in premature senescent cells partially overcame endothelial cell senescence. p53 knockdown, but not p16 knockdown, abolished senescence phenotypes caused by XAF1 induction. XAF1 expression was transcriptionally regulated by Bromodomain 7 (BRD7). XAF1 induction with interferon-gamma (IFN-y) treatment was abrogated by BRD7 knockdown, which resulted in blocking interferon-induced senescence. In lung cancer cells, XAF1 tumor suppressor activity was decreased by BRD7 knockdown, and inhibition of tumor growth by IFN-Y did not appear in BRD7-depleted xenograft tumors. These data suggest that XAF1 is involved in BRD7-associated senescence and plays an important role in the regulation of endothelial senescence through a p53-dependent pathway. Furthermore, regulation of the BRD7/XAF1 system might contribute to tissue or organismal aging and protection against cellular transformation.

\section{INTRODUCTION}

Normal somatic cells cultured in vitro have a limited ability to divide before entering a state of irreversible proliferative arrest termed replicative senescence [1]. Replicative senescence is induced by telomere attrition, response to activated oncogenes and DNA damage, deregulated nutrient sensing, loss of proteostasis and epigenetic alterations during aging [2-4].

Irreversible growth arrest is induced in primary cells through the expression of activated oncogenes such as Ras [5] or by activation of tumor suppressor genes [6]. Numerous studies have implicated the tumor suppressors p53, p16 and Rb as common major effectors of cellular senescence in normal somatic cells [7-8]. In this study, we used genetic approaches to search for previously unexplored senescence regulators in endothelial cells, particularly those involved in BRD7-associated senescence.

Bromodomain 7 (BRD7) is a unique component of the SWI/SNF polybromo-associated BRG1-associated factor (PBAF) complex that contributes to proliferation regulation [9]. It was originally identified as a gene whose mRNA was downregulated in nasopharyngeal carcinoma [10]. Recent studies have implicated BRD7 as a regulator of replicative senescence based on the induction of resistance to Ras-induced senescence by BRD7 depletion [11] or the induction of oncogene-induced senescence through BRD7 interaction with p53 and p300 [12].

Bromodomains are evolutionally conserved domains that have specific binding affinity for acetylated lysines on histone N-terminal tails [13]. Although the function of bromodomains still requires further investigation, bromodomain proteins modulate chromatin remodeling and modification, thereby facilitating accession of transcription factors to chromatin [14-16].

$\mathrm{X}$-linked inhibitor of apoptosis (XIAP)-associated factor 1 (XAF1) directly and indirectly regulates p53mediated apoptosis as a tumor suppressor gene. XAF1 is expressed ubiquitously in all healthy adult and fetal 
tissues, but is lost or reduced in a variety of cancer cell lines because of the aberrant promoter hypermethylation of its gene [17-18]. XAF1 was originally identified as a nuclear protein that has the ability to bind XIAP and antagonize the ability of XIAP to suppress caspase activity and cell death [18]. XAF1 can also induce apoptosis through an alternative pathway by enhancing TNF-alpha independently of interaction with XIAP [19].

Despite previous reports showing the implications of XAF1 in p53-mediated apoptosis in cancer, the molecular and cellular effects of XAF1 in primary normal vascular endothelial cells have not been examined. In the current study of the transcriptional regulation by BRD7 in endothelial cell senescence during irradiation, we have found a correlation between XAF1 and BRD7 in radiationinduced senescence. In this study, we demonstrate that XAF1 plays a crucial role in cellular senescence through transcriptional regulation by BRD7 in human endothelial cells.

\section{RESULTS}

\section{XAF1 expression increases during DNA damage- induced senescence in endothelial cells}

To investigate whether XAF1 is associated with cellular senescence in pulmonary endothelial cells, we examined XAF1 expression levels in young and old cells by semi-quantitative PCR (q-PCR), real-time PCR and Western blot analysis. Senescent cells are known to be resistant to mitogen-induced proliferation, express SA$\beta$-gal and have a characteristically enlarged and flattened morphology. Using serial passaging with trypsinization, senescent cells (also referred to herein as 'old cells') were obtained and characterized by p53/p21 activation and SA$\beta$-gal staining (Figure 1A, 1B). XAF1 protein levels were upregulated 3 -fold or more in the old endothelial cells

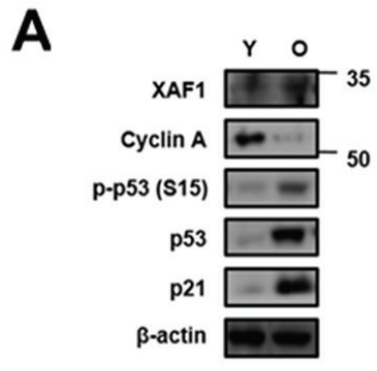

B
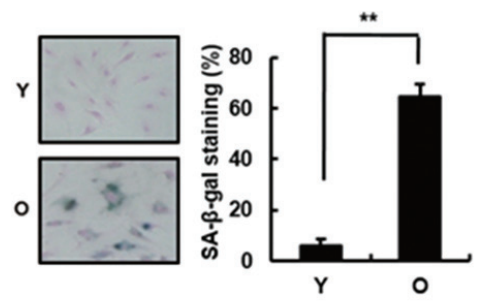

C

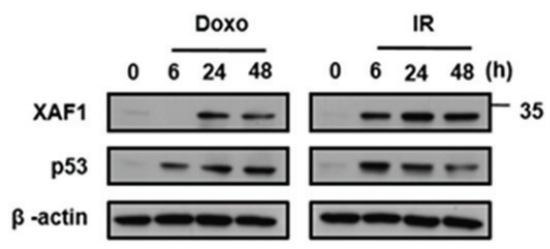

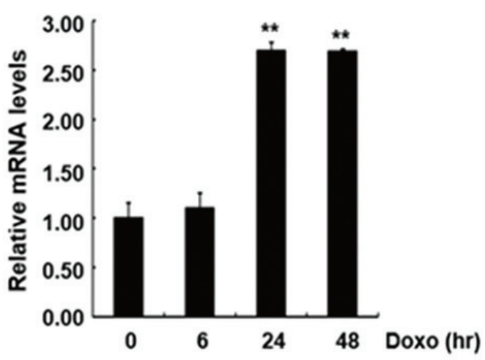

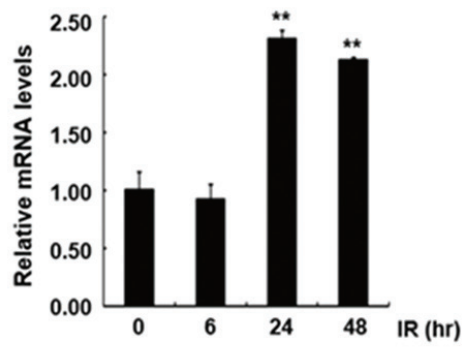

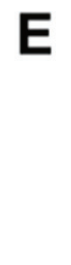
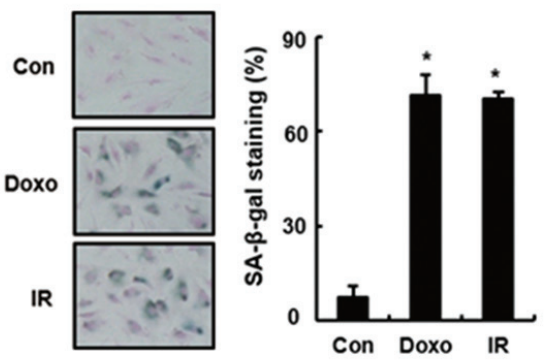

Figure 1: Increase in XAF1 expression in cellular senescence. A. XAF1 protein expression levels XAF1 were analyzed by Western blotting with antibodies against XAF1 and GAPDH (loading control) in aged HMVECs. The levels of cyclin A, phospho-p53(S15), p53, p21 and $\beta$-actin proteins were detected by Western blot analysis. The figure shows representative data from three independent experiments. B. Percentages of SA- $\beta$-gal positive cells analyzed in young and old HMVECs. ${ }^{*} p<0.01$ versus the young cells. C. XAF1 and p53 protein expression levels were detected by Western blot analysis. D. HMVECs treated with doxorubicin (Doxo, $1 \mu \mathrm{M}$ ) or ionizing radiation (IR, 4 Gy). The cells were incubated for 0,24 or 48 h, and the XAF1 mRNA expression levels were measured by semi-quantitative PCR and real-time PCR analyses. Values are expressed as the mean \pm SD of three independent experiments. $* * p<0.01$ versus the control group without Doxo or IR treatment. E. After treatment with Doxo or IR for 4 days, Percentages of SA- $\beta$-gal positive cells analyzed in young and premature senescent cells. ${ }^{*} p<0.05$ versus the control cells. Y, young cells; $\mathrm{O}$, old cells. 
(Figure 1A). XAF1 expression was increased by DNA damaging agents, such as doxorubicin (Doxo) and ionizing radiation (IR) [20-21], which induced cellular senescence in endothelial cells (Figure 1C). These cells showed senescent phenotypes that distinguished them from the early-passage cells. Doxo or IR treatment increased XAF1 protein and mRNA levels in a time-dependent manner (Figure 1C, 1D) and resulted in morphological changes in old cells and increases in SA- $\beta$-gal staining activity (Figure 1E). These results imply that XAF1 upregulation is implicated in cellular senescence in old and IR-treated endothelial cells.

\section{Effects of XAF1 upregulation on cellular senescence in HMVECs}

Because XAF1 expression levels were increased in senescent cells and by treatment with the DNA damagerelated senescence inducers Doxo and IR, we tested whether XAF1 overexpression has an impact on cellular senescence in HMVECs. HMVECs were transduced with XAF1 lentivirus, and senescence markers in XAF1overexpressing cells were examined. XAF1 upregulation caused a decrease in cell proliferation and an increase in SA- $\beta$-gal staining compared with the control lentivirustransduced cells (Figure 2B, 2C). Increased XAF1 expression induced the expression of cell cycle regulators, such as p53 and p21, and inhibited the expression of Cyclin A (Figure 2A), resulting in G0/G1 cell-cycle arrest but not apoptosis (Figure 2D, 2E). Taken together, these results suggest that XAF1 might play an important role in inducing senescence in HMVECs.

\section{XAF1 knockdown reverses premature senescence in HMVECs}

To investigate the role of XAF1 in cellular senescence, HMVECs were treated with two DNA damage
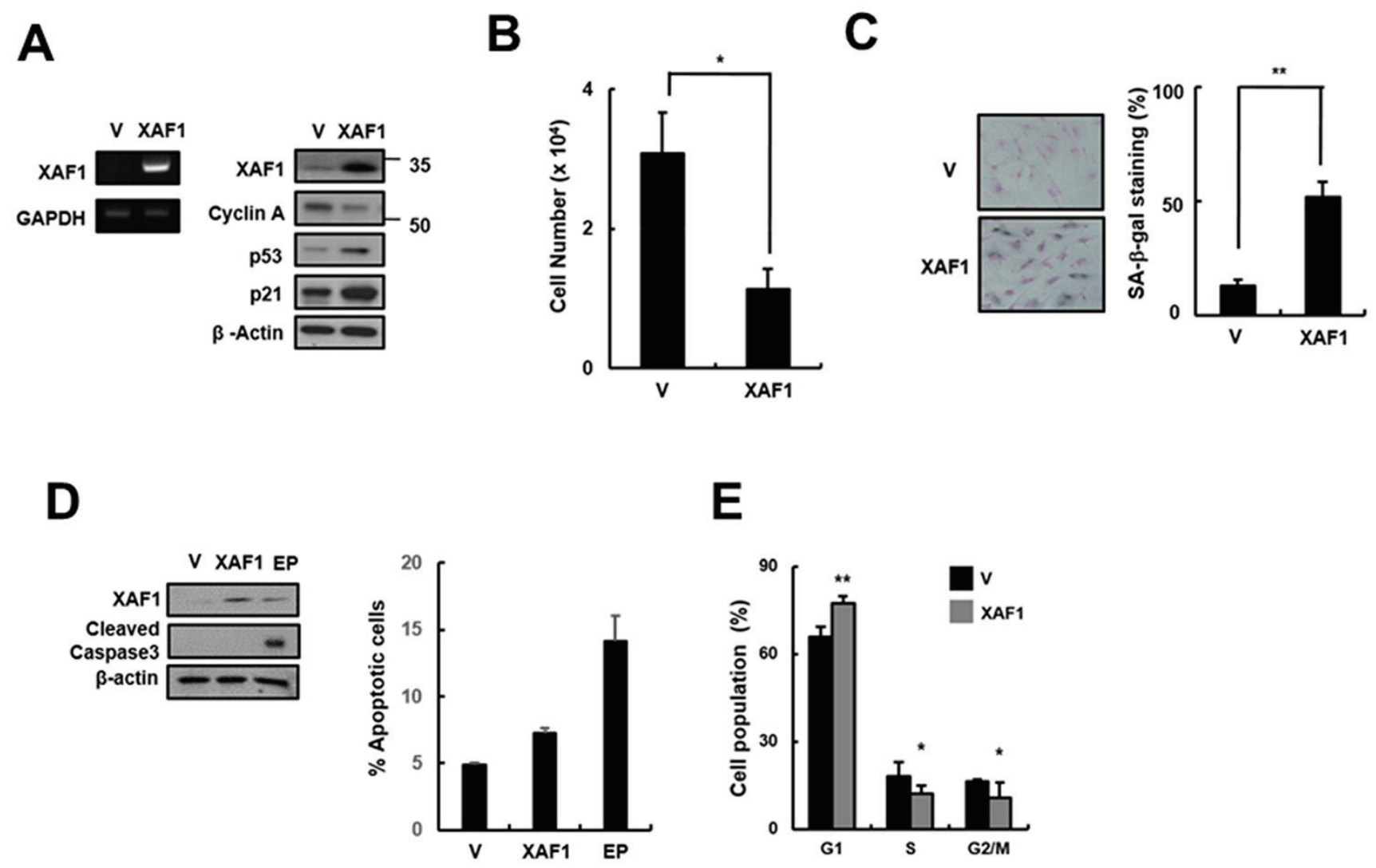

Figure 2: Effects of XAF1 on the upregulation of cellular senescence in young HMVECs. A. Young cells were transduced with XAF1 or negative control lentiviruses and incubated for 3 days. XAF1 mRNA expression levels were measured by semi-quantitative PCR and XAF1, cyclin A, p53 and p21 protein levels were detected by Western blot analysis. B. Cell proliferation was measured by cell counting and $\mathbf{C}$. the percentages of SA- $\beta$-gal positive cells were analyzed. ${ }^{*} p<0.05$ and $* *<0.01$ versus the vector group. D. XAF1transduced cells were stained with Annexin V-FITC and propidium iodide (PI). To measure apoptosis, fluorescence intensities of Annexin V-FITC were analyzed by flow cytometry. Etoposide $(\mathrm{EP}, 100 \mu \mathrm{M})$ was used as a positive treatment. Cleaved caspase 3 activity was analyzed by Western blot. E. Cell cycle profiles were analyzed by PI staining and flow cytometry. Values are expressed as the mean \pm SD of three independent experiments. Representative data from three independent experiments are shown. ${ }^{*} p<0.05$ and $* * p<0.01$ versus the vector group. V, control vector lentivirus-transduced cells; XAF1, XAF1 lentivirus-transduced cells. 
agents (Doxo and IR) that trigger premature senescence. XAF1 mRNA and protein levels were downregulated by gene silencing using XAF1 siRNAs in the senescent cells. The Doxo- and IR-induced increase in p53 expression and activation was reduced in the XAF1 knockdown cells (Figure 3A). Decreased cell proliferation in Doxoor IR-treated cells was partially recovered by XAF1 downregulation (Figure 3B). Repression of XAF1 levels in senescent cells caused morphological changes similar to young cells and a decrease in SA- $\beta$-gal activity (Figure 3C). Additionally, XAF1 downregulation in premature senescent cells decreased the population of cells in the G1 phase and increased the population of cells in the $\mathrm{S}$ and $\mathrm{G} 2 / \mathrm{M}$ phases (Figure 3D). These results suggest that XAF1 knockdown in old cells partially reverses senescence phenotypes.

\section{XAF1 induces cellular senescence through a p53 signaling pathway}

The p53 and $\mathrm{Rb}$ tumor suppressor pathways play critical roles in activating senescence response [22]. It is reasonable to expect that XAF1 activates specific signaling pathways to engage $\mathrm{p} 21$ via $\mathrm{p} 53$ protein and/or $\mathrm{p} 16 / \mathrm{Rb}$ proteins. To determine which pathway is involved in XAF1-mediated cellular senescence, we knocked down p16 and p53 using shRNA retroviruses in HMVECs and measured the effects of XAF1 on cellular senescence (Figure 4A). The p16 knockdown cells showed a decrease in cell proliferation by overexpressing XAF1 similar to the control cells. In contrast, XAF1 overexpression had no effect on cell proliferation in the p53 knockdown cells (Figure 4B). By measuring the SA- $\beta$-gal activity, we demonstrated that p53 knockdown inhibited XAF1induced cellular senescence but p16 knockdown did not (Figure 4C). Therefore, these results suggest that XAFinduced cellular senescence might be mediated through a p53-dependent pathway.

\section{The role of BRD7 in XAF1 transcriptional regulation}

BRD7 acts a transcriptional cofactor of promoter activity for a subset of p53 target genes [23]. We recently identified BRD7 as a potential regulator of DNA damageinduced senescence in endothelial cells. Using DNA microarray analysis, we compared the gene expression profiles from BRD7 down- or upregulated cells to identify
A
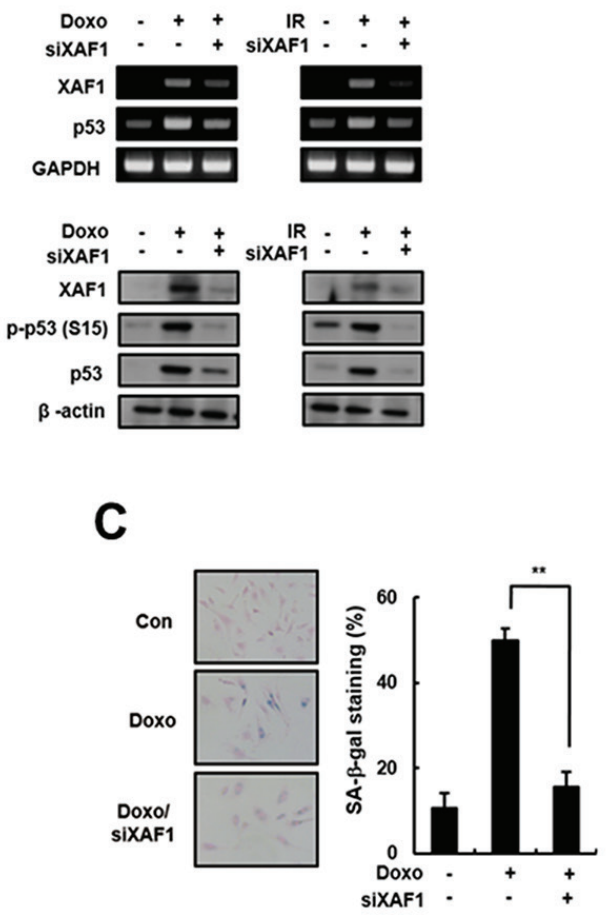

B
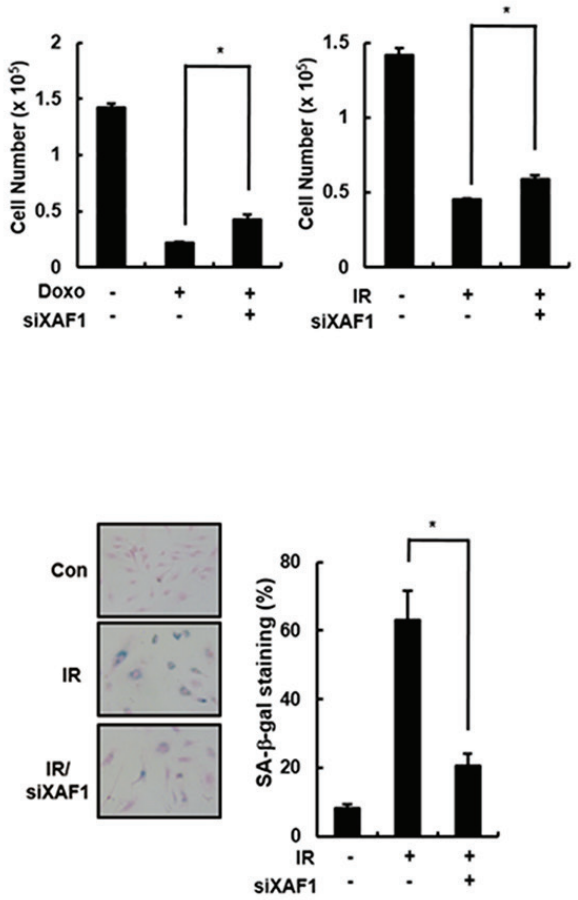

D
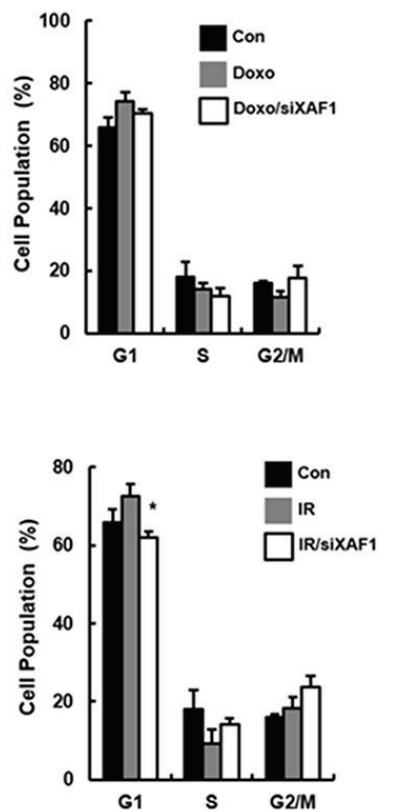

Figure 3: Partial reverse of premature senescence by XAF1 downregulation in HMVECs. A. HMVECs treated with doxorubicin (Doxo, $1 \mu \mathrm{M}$ ) or ionizing radiation (IR, $4 \mathrm{~Gy}$ ). The cells were incubated for $48 \mathrm{~h}$ before transfection with XAF1 siRNAs (siXAF1) or negative control siRNAs. XAF1 knockdown in Doxo- or IR-treated cells was confirmed by RT-PCR (upper panel) and Western blot analysis (lower panel). B. Effects of XAF1 knockdown on premature senescence by Doxo or IR in XAF1 siRNAs-transfected cells were examined by cell proliferation and C. SA- $\beta$-gal staining (100x). D. Cell cycle profiles were analyzed by PI staining and flow cytometry. The figure shows representative data from three independent experiments. Values are expressed as the mean \pm SD of three independent experiments. ${ }^{*} p<0.05$ and $* * p<0.01$ versus the siRNA control group. 
DNA damage-related genes transcriptionally regulated by BRD7. As shown in Figure 5A, we selected several genes that were potentially regulated by BRD7 and confirmed the expression of each gene in BRD7 down- or upregulated HMVECs using real time PCR. One of these genes, XAF1, was verified to be a BRD7-regulated gene. Interferon regulatory factor 1 (IRF1) is known to be an XAF1 transcription factor and is induced by interferon stimulation. Similar to cells treated with interferon-gamma (IFN- $\gamma$ ), BRD7 could induce XAF1 expression (Figure 5B). To test whether BRD7 exerts a direct influence on
XAF1 expression, we measured XAF1 expression when BRD7-downregulated cells were treated with IFN- $\gamma$. Despite the presence of IFN- $\gamma$ stimulation, XAF1 was downregulated by BRD7 depletion, suggesting that BRD7 may mediate a direct effect on XAF1 expression (Figure 5C). Using chromatin immunoprecipitation (ChIP) (Figure $5 \mathrm{D}, 5 \mathrm{E}$ ) and luciferase assays (Figure 5F), we further confirmed transcriptional regulation of XAF1 by the BRD7 protein. Consequently, the BRD7 protein increased the promoter activity of the XAF1 gene. Therefore, BRD7 is required for XAF1 transcriptional expression.
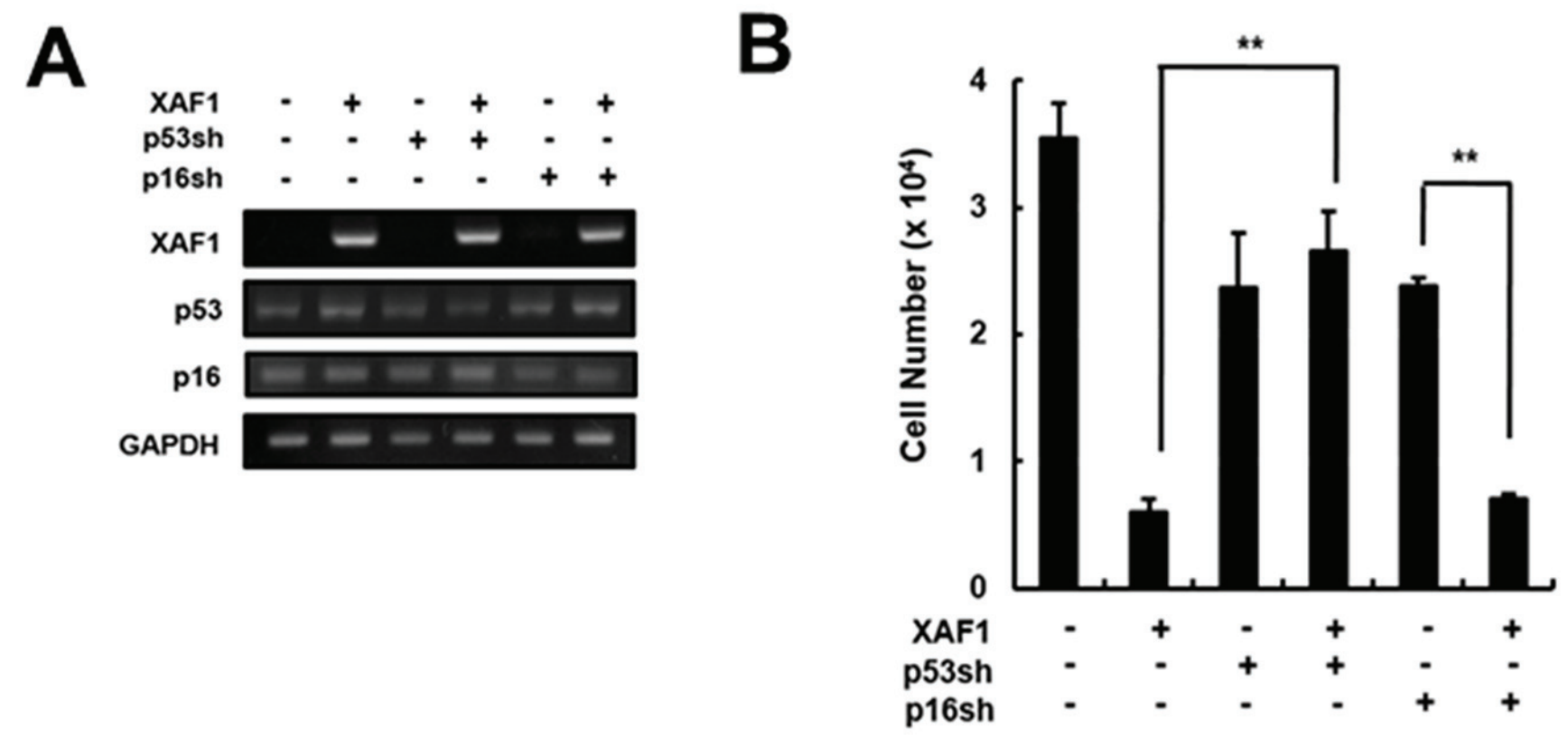

C
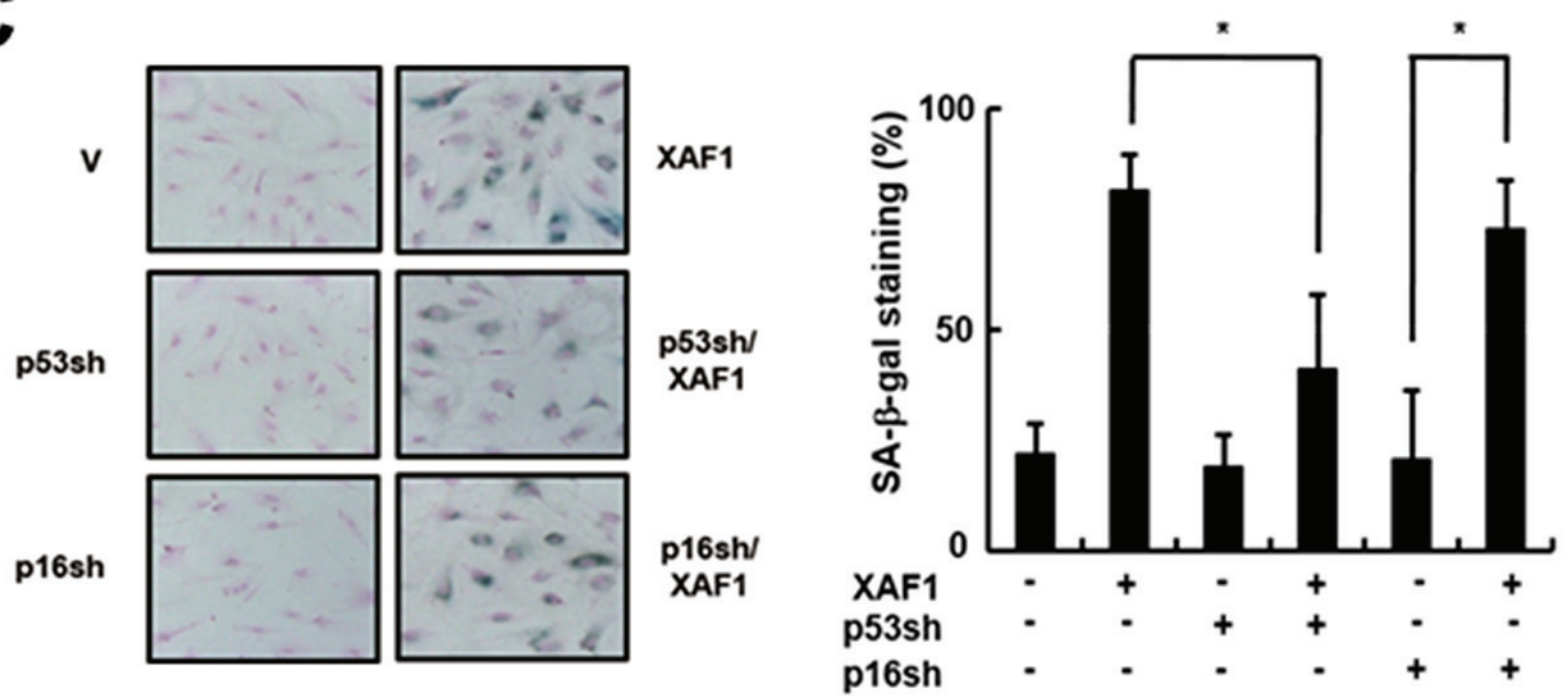

Figure 4: Effects of p53 or p16 knockdown on cell growth arrest induced by XAF1. A. Cells were transduced with p53or p16-shRNA retroviruses and incubated for 2 days. P53 and p16 knockdown was confirmed by RT-PCR analysis. The p53- or p16downregulated cells were transduced with XAF1 or negative control lentiviruses and incubated for 2 days. Cell proliferation was measured by B. cell counting for 2 days and C. SA- $\beta$-gal staining (100x). Values are expressed as the mean \pm SD of three independent experiments. Representative data from three independent experiments are shown. ${ }^{*} p<0.05$ and ${ }^{*} p<0.01$ versus XAF1 overexpression. p53sh, p53shRNA retrovirus transduced cells; p16sh, p16-shRNA retrovirus transduced cells. 
A
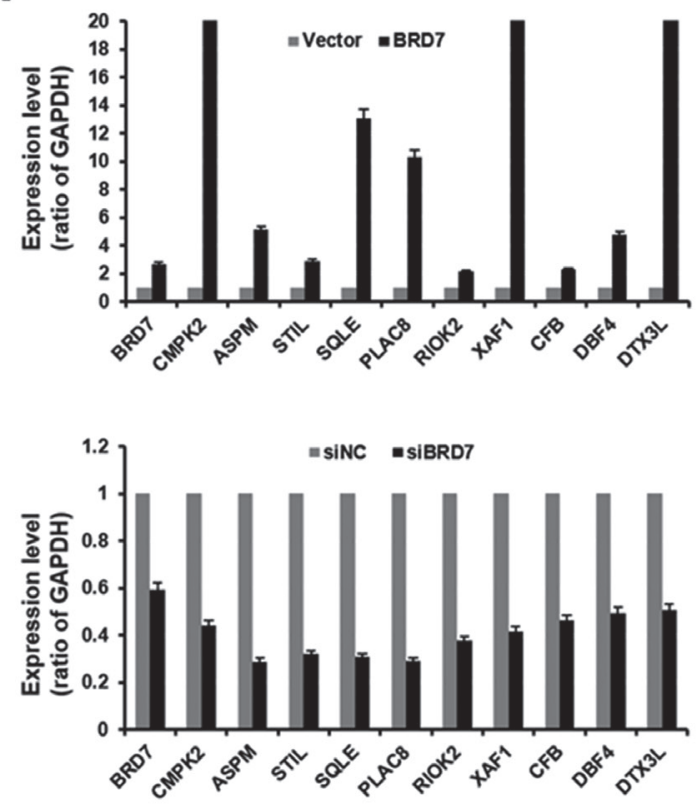

B
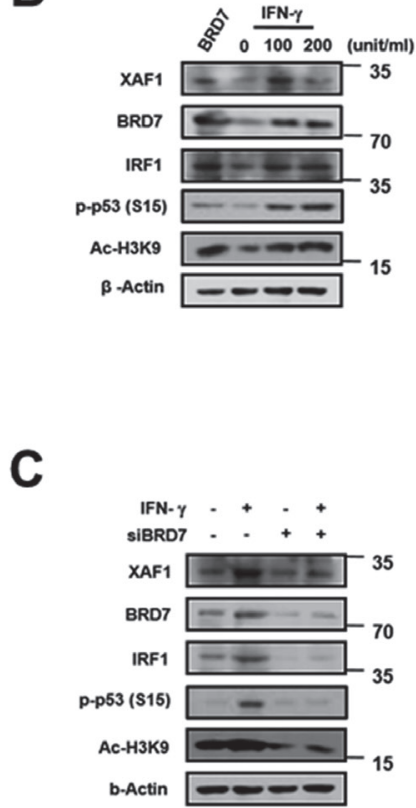

D

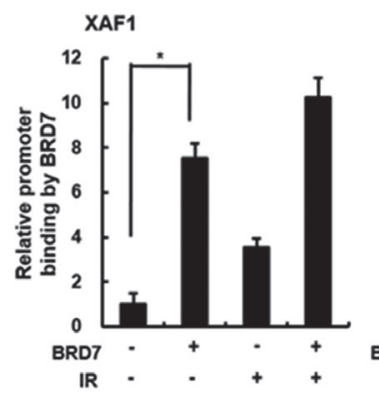

E

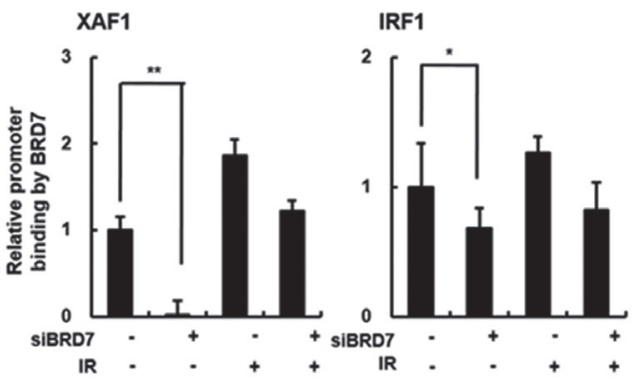

$\mathbf{F}$
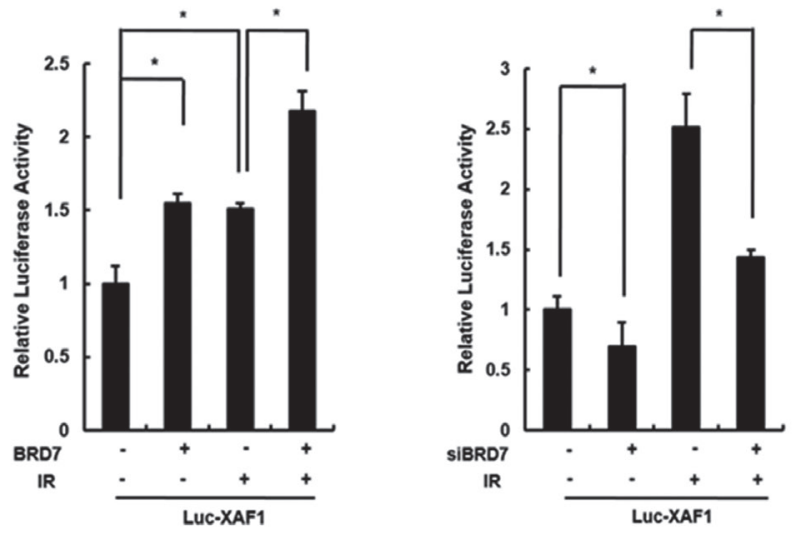

Figure 5: Transcriptional regulation of XAF1 by BRD7. A. XAF1 was upregulated with BRD7 lentivirus or downregulated with BRD7 siRNAs in HMVECs. BRD7, CMPK2, ASPM, STIL, SQLE, PLAC8, RIOK2, XAF1, CFB, CBF4 and DTX3L expression levels were analyzed by real time-PCR. Each of the expression levels were normalized to GAPDH expression levels. B. Cells were transduced with BRD7 lentivirus or treated with 0,20 or $100 \mathrm{ng} / \mathrm{ml}$ interferon-gamma (IFN- $\gamma$ ) for $24 \mathrm{~h}$. XAF1, BRD7, IRF1, phospho-p53 and AcH3K9 protein levels were detected by Western blot analysis. C. Cells were transfected with BRD7 siRNAs and treated with IFN- $\gamma$ for $24 \mathrm{~h}$. XAF1, BRD7, IRF1 and phsopho-p53 protein levels were detected by Western blot analysis. D. Cells were transduced with BRD7 lentivirus or transfected with BRD7 siRNAs. Each of cells was treated with 4 Gy IR for 24 h. Chromatin immunoprecipitation (ChIP) assay was performed using the anti-BRD7 antibody and the immunoprecipitated DNA was amplified using primers for p53, IRF1 or XAF1. E. The cells were transfected with the luciferase reporter constructs containing the XAF1 promoter. XAF1 promoter activity in BRD7-expressed cells was determined by luciferase analysis. ${ }^{*} p<0.05$ and $* * p<0.01$ versus the siRNA control group. 


\section{XAF1 as a tumor suppressor gene in lung cancer cells}

$\mathrm{XAF} 1$ is a tumor suppressor that is frequently silenced in many human cancers, but it can inhibit cell proliferation and induce apoptosis in some cancer types. XAF1 increases sensitivity to IR in lung cancer cells, but its effect in lung cancer remains unclear. We tested the cellular effects of XAF1 expression in the human lung cancer cell line A549. Similar to its effect in HMVECs, XAF1 expression increased p21 expression (Figure 6A), induced cell cycle arrest (Figure 6B) and increased SA$\beta$-gal staining (Figure 6C) in A549 cells. To investigate whether BRD7 acts as critical regulator of XAF1 in lung cancer cells, we examined migration and invasion by transfecting BRD7 siRNAs into cells overexpressing XAF1. XAF1 decreased migration and invasion ability in lung cancer cells, although the increase in XAF1 expression, migration and invasion was not reduced by BRD7 depletion (Figure 6D, 6E). Unlike in HMVECs, XAF1 induced apoptosis in lung cancer cells (Figure 6F). Therefore, these results suggest that BRD7 expression plays a critical role in XAF1 tumor suppression.
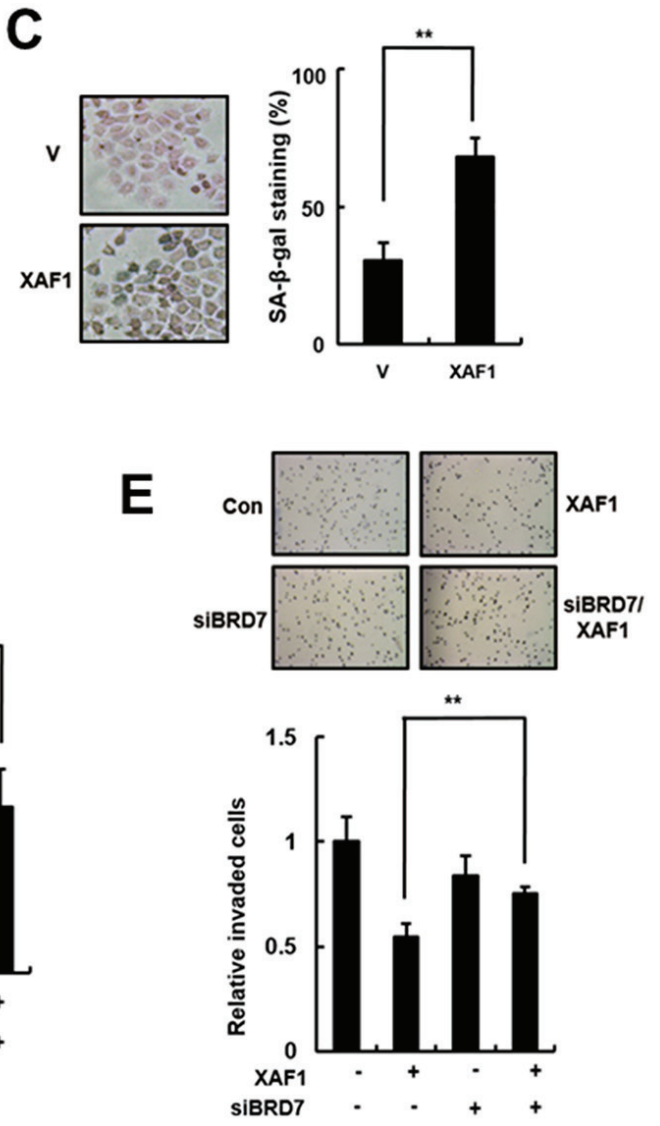

$\mathbf{F}$

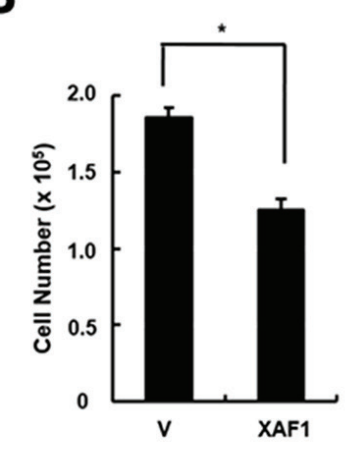

D
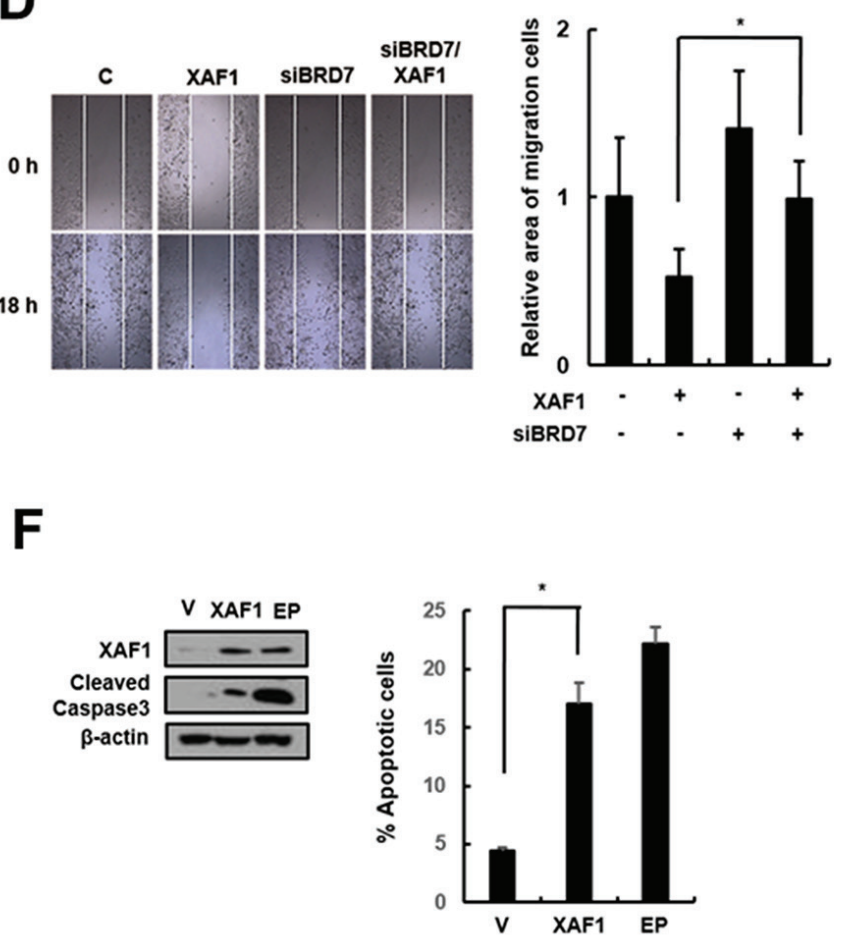

Figure 6: Effects of XAF1 expression in lung cancer cells. A. XAF1 was upregulated in A549 lung cancer cells and its expression levels were confirmed by semi-quantitative RT-PCR and western blot analysis. Cell proliferation was measured by B. cell counting for 2 days and C. SA- $\beta$-gal staining (100x) and the percentage of SA- $\beta$-gal positive cells were analyzed in XAF1 upregulated cells $\mathbf{C} .{ }^{*} p<0.05$ and $* * p<0.01$ versus the vector group. D. Cell migration and E. invasion assays were performed with the XAF1 upregulated cells. ${ }^{*} p<$ 0.05 and $* * p<0.01$ versus XAF1 overexpression. F. Cleaved caspase 3 activity was analyzed by Western blot. Percentage of apoptosis cells was analyzed by flow cytometry with Annexin V-FITC. Etoposide (EP) was used as a positive treatment. ${ }^{*} p<0.05$ versus vector group. 


\section{Effects of BRD7-regulated XAF1 in animal model tumors}

As shown in Figure 5, XAF1 is regulated by IFN- $\gamma$, meaning that IFN- $\gamma$ is a good tool for inducing XAF1. Because IFN- $\gamma$-induced XAF1 is a potential radiosensitizer in lung cancer cells [24], we tested whether BRD7 can affect the radio-sensitizing activity of IFN$\gamma$-induced XAF1. After IFN- $\gamma$ treatment, XAF1 protein levels were regulated by BRD7 depletion (Figure 7A). Following IR, a colony forming assay showed that IFN- $\gamma$ treatment decreased clonogenic cell survival in A549 lung cancer cells but that BRD7 depletion inhibited the decrease in clonogenic cell survival induced by IFN- $\gamma$ treatment (Figure 7B). With INF- $\gamma$ treatment, we confirmed that BRD7 regulates the tumor suppression activity of XAF1 in vivo. A549 cells were transduced with BRD7 or control shRNA lentiviruses, selected with puromycin and then established as A549 xenografts in

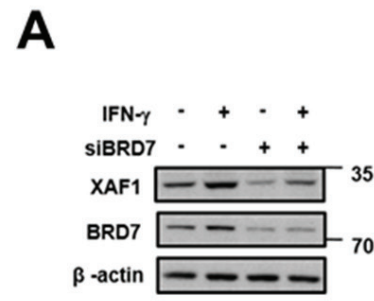

B
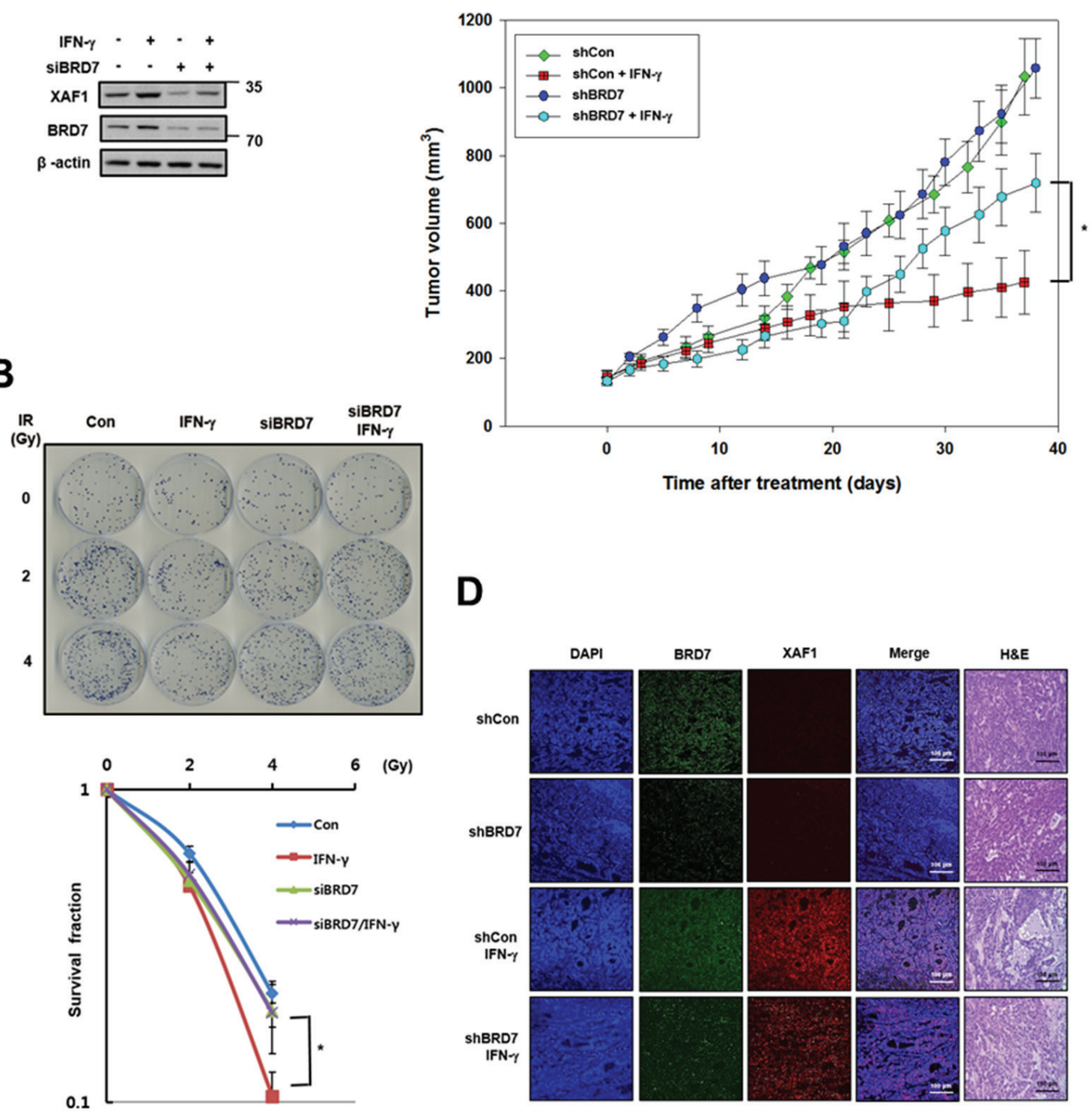

Figure 7: Effects of BRD7-dependent XAF1 expression in vivo. A. A549 cells were transfected by BRD7 siRNA (siBRD7) or scramble siRNA and then each of the cells was treated with IFN- $\gamma(100 \mathrm{ng} / \mathrm{ml})$. Expression of XAF1 and BRD7 proteins were confirmed by Western blotting. B. Each of the cells was irradiated with 0, 1,2 and 4 Gy of IR, and incubated about 2 weeks for colony formation. Cell survival values were normalized to those of the unirradiated cells. ${ }^{*} p<0.05$ versus BRD7-depleted group. C. Effect of IFN- $\gamma$ administration on growth of A549 tumor xenografts in nude mice. Nude mice ( $n=10$ per group) were implanted subcutaneously with A549 and groups of mice received vehicle or IFN- $\gamma\left(1 \times 10^{5}\right.$ unit $)$ three times for a week. Tumor size was assessed by direct caliper measurement. Data are means $\pm \mathrm{SE}, n=10$. Tumor volume between shCon and shBRD7 in IFN- $\gamma$ treated group was statistically significantly different at $* p<0.05$ by two-sided Student's $t$-test. D. Xenograft tumors were embedded with paraffin, were serially sectioned and stained with hematoxylin and eosin (H\&E). The tissue samples were immunostained with XAF1 and BRD7 antibodies and observed with fluorescence microscope. 
nude mice. The change in tumor volume was monitored three times a week after INF- $\gamma$ treatment. Tumor growth was significantly suppressed by INF- $\gamma$ treatment, but BRD7 depletion prevented the decrease in tumor growth by INF- $\gamma$ treatment (Figure 7C). Xenograft tumors were processed for histology and stained with hematoxylin and eosin (H\&E) or immunostained with XAF1 and BRD7 antibodies (Figure 7D). H\&E staining demonstrated that tumor necrosis induced by IFN- $\gamma$ treatment was decreased in the BRD7-depleted group and that IFN- $\gamma$-induced XAF1 expression was not shown in BRD7-depleted tumors. These observations indicate that INF- $\gamma$-induced $\mathrm{XAF} 1$ and that XAF1 tumor suppression is determined by $\mathrm{BRD} 7$ in vitro as well as in vivo.

\section{DISCUSSION}

Along with surgery and chemotherapy, radiation therapy (radiotherapy) is one of the most important methods for cancer treatment. Currently, more than half of all cancer patients receive radiation therapy. Radiation kills cancer cells by damaging their DNA, but it can also damage normal cells and some tissue types. It is not easy to balance the two conflicting effects during cancer therapy. Exposure to ionizing radiation leads to adverse physiological responses, such as cancer, gastrointestinal failure, bone marrow failure and accelerated aging, but these risks are not exclusively a result of radiotherapy. Generally, the radiation-associated excess relative risks are lower than excess absolute risks in medically exposed individuals [25]. Therefore, it is important to improve radiotherapy to increase the curative and survival rates for patients.

Thus, we have to consider endothelial cell function in the opposite point of view in cancer and vascular diseases. In cancer biology, endothelial cells are homeostatic factors for regulating angiogenesis-dependent tumor growth [26]. Microvascular damage regulates tumor cell response to radiation, and radiation-induced vascular damages enhance rapid apoptosis in tumors and prevent the recurrence of tumors after radiation treatment [27]. In this study, increased XAF1 was associated with the induction of a variety of senescent phenotypes, including growth arrest by $\mathrm{p} 53$ activation and an increase in senescence-associated $\beta$-galactosidase (SA- $\beta$-gal) staining in both pulmonary endothelial cells and lung cancer cells (Figures 2, 7). Therefore, XAF1 may be a potential inhibitor of angiogenesis and tumor growth because XAF1 binds directly to p53 and induces p53-mediated apoptosis in cancer.

In contrast, senescent cells have been suggested to contribute to aging-associated pathologies via the accumulation of non-dividing cells and alterations in tissue structure and function [8]. Therefore, endothelial cell senescence contributes to the age-related decline of vessel structure and the progression of various age- associated vascular diseases. XAF1 induces endothelial cell senescence, suggesting that XAF1 may contribute to vascular aging and the development of aging-associated vascular diseases.

Recently, several groups have reported that radiation induces senescence in endothelial cells. Endothelial cell senescence is associated with vascular damage and vascular disease in vivo. DNA damaging agents, such as ionizing radiation, can accelerate the onset of endothelial cell senescence through numerous changes in protein expression [28]. We have examined the biological networks that are affected by ionizing radiation from epigenetic alteration. Aging is associated with profound epigenetic changes, resulting in extensive remodeling of gene-expression profiles and disturbances in broad epigenomic landscapes. The relationship between epigenetic changes and aging has been confirmed by changes in DNA methylation levels [29], histone levels and their post-translational modifications [30] and transcriptional gene silencing by non-coding RNAs [31]. Among them, histone modifications directly contribute to nuclear compartmentalization for the formation of chromatin domains, such as heterochromatin and euchromatin, which are transcriptionally silent and active, respectively [32]. Specifically, with respect to histone modifications and aging, increased H3K9 acetylation leads to shortened life span and premature aging-like phenotypes in response to DNA damage [33]. Conversely, $\mathrm{H} 3 \mathrm{~K} 9$ di- and tri-methylation are reduced by DNA damage and replicative aging [34]. Furthermore, H3K4 demethylation can induce the transcriptional silencing of the retinoblastoma target genes in senescent cells [35] and methylated $\mathrm{H} 3 \mathrm{~K} 36$ can regulate cell proliferation and senescence via the p53 and Rb pathways [36].

BRD7 is a selected marker for both cellular senescence and DNA damage response for epigenetic studies with radiation-induced senescence. BRD7 participates in chromatin remodeling by binding to acetylated histones and regulates the expression of genes as a transcription factor. Using genechip arrays and chromatin immunoprecipitation analysis, we have newly founded that XAF1 is transcriptionally increased by BRD7 during radiation exposure (Figure 4).

Although there is not known for epigenetic alteration by BRD7, the reversibility of epigenetic modifications and gene expression by BRD7 inhibition will provide a new possibility for therapeutic interventions in age-related diseases as well as radiation damage regulation. 


\section{MATERIALS AND METHODS}

\section{Materials}

Human lung microvascular endothelial cells (HMVECs) and endothelial cell basal medium-2 (EBM2) supplemented with endothelial growth medium 2 (EGM-2) were obtained from Lonza (Walkersville, MD, USA). Roswell Park Memorial Institute medium (RPMI 1640), fetal bovine serum (FBS), $100 \mathrm{U} / \mathrm{ml}$ of penicillin and $100 \mu \mathrm{g} / \mathrm{ml}$ of streptomycin were purchased from Welgene (Daegu, Korea). Antibodies against XAF1 (sc19194), BRD7 (sc-376179), IRF-1 (sc-497), cyclin A (sc-239), p53 (sc-126), p21 (sc-397) and beta-actin (sc81178) were from Santa Cruz Biotechnology Inc. (Santa Cruz, CA, USA), and antibodies against phospho-p53 (Ser15) (\#9248), acetylated lysine 9 of histone H3 (AcH3K9) (\#9649) and cleaved Caspase3 (\#9661) were from Cell Signaling Technology Inc. (Danver, MA, USA). Horseradish peroxidase-conjugated secondary rabbit, mouse and goat antibodies were from Bethyl Laboratories, Inc. (Montgomery, TX, USA). XAF1 siRNA (AUGAAGGAAGAAUUUCUGGAUUUCC) and Lipofectamine 2000 reagent were from Invitrogen Life Technologies Inc. (Carlsbad, CA, USA), and the pLKO.1shBRD7 vectors (TRCN0000360087) were from SigmaAldrich (St. Louis, MO, USA). BRD7 siRNA (L-02029700) was from GE Dharmacon (Lafayette, CO, USA). The PCR primers for XAF1, p53, p16 and GAPDH were obtained from Bioneer (Daejeon, Korea). We obtained bromo-chloro-indolyl-galacto-pyranoside (BCIG; X-gal) from Duchefa (Haarlem, Netherlands), a total RNA isolation (TRI) solution from Molecular Research Center, Inc. (Montgomery, CA, USA) and a reverse transcriptionpolymerase chain reaction kit from the Promega Corp. (Madison, WI, USA).

\section{Cell culture}

HMVECs in EBM-2 supplemented with EGM-2 and A549s in RPMI 1640 were plated at a density of $2 \mathrm{x}$ $10^{5}$ cells per $100 \mathrm{~mm}$ culture plate and cultured at $37^{\circ} \mathrm{C}$ in a $5 \% \mathrm{CO}_{2}$ humidified incubator. When the subcultures reached $80 \%$ confluence, serial passaging was performed by trypsinization. For experiments, cells were used in either passage 5-7 ( $\mathrm{PD}<24$; young) or passage 12-15 (PD $>48$; old).

\section{Induction of cellular senescence by adriamycin treatment and $\gamma$-ray irradiation}

HMVECs and A549s ( 2 × $10^{5}$ cells $)$ were seeded in $60-\mathrm{mm}$ culture dishes and incubated for $24 \mathrm{~h}$ in culture media. The cells were washed with media and treated with $1 \mu \mathrm{M}$ doxolubicin (Doxo) for $4 \mathrm{~h}$. After discarding the media containing the Doxo, the cells were washed 3 times with media and incubated in culture media for the indicated times. For ionizing radiation (IR) treatment, cells were exposed to $\gamma$-rays with a 137 Cs $\gamma$-ray source (Atomic Energy of Canada, Ltd.) at a dosage of $3.81 \mathrm{~Gy} /$ $\min$.

\section{Virus preparation and transduction}

For XAF1 overexpression, the XAF1 transcript was cloned into a pLenti6/V5-TOPO vector (Life Technologies Corporation, Carlsbad, CA, USA). Cells were transduced with XAF1 lentivirus for 48 h. p16 and p53 shRNA retroviruses were prepared by transfection of the pRetroSuper-p53sh and pRetroSuper-p16sh vectors. After incubation for 3 days, media were collected and centrifuged at $1,650 \mathrm{~g}$ for $10 \mathrm{~min}$. The viral solution was filtered with $0.45-\mu \mathrm{m}$ filter membranes and concentrated with a Vivaspin 20 (Sartorius, Goettingen, Germany).

\section{Cell counting}

Cells were harvested by trypsin-EDTA treatment and stained with $0.1 \%$ trypan blue, and the cell number was determined using a hemocytometer.

\section{Clonogenic cell survival assay}

A clonogenic cell survival assay was performed by following a standard protocol [37].

\section{Invasion and migration assay}

Cell invasive activities were assessed using a 12-well Transwell ${ }^{\circledR}$ insert from Corning Life Sciences (Lowell, MA, USA). Cells were seeded in the absence of serum at a concentration of $2 \times 10^{5}$ cells in the upper chamber. The lower chamber was filled with culture medium supplemented with 10\% FBS. After 24 hours, invaded cells that had passed through the Matrigel were fixed with methanol, stained with $0.1 \%$ crystal violet, and counted under a light microscope (200× magnification). For the migration assay, cells were seeded at a density of 1 x $10^{6}$ cells in a 12-well dish. Scratch wounds were created with pipette tips through the confluent cells. Migration/ wound-healing was observed after $24 \mathrm{~h}$.

\section{Immunofluorescence staining}

Cells were fixed with $3.7 \%$ para-formaldehyde in PBS for 3 min and permeabilized in PBS containing 
$0.5 \%$ Triton X-100 for $5 \mathrm{~min}$. The cells were incubated with an antibody specific to XAF1 (1:200) for $2 \mathrm{~h}$ and then with Alexa Fluor ${ }^{\circledR} 594$ donkey anti-Goat IgG (1:300) (Life Technologies, Carlsbad, CA, USA) for $30 \mathrm{~min}$. The nuclei were stained with $0.1 \mu \mathrm{g} / \mathrm{ml}$ of 4',6-diamidino-2phenylindole (DAPI) for $5 \mathrm{~min}$. Images were obtained using a fluorescence microscope.

\section{Senescence-associated $\beta$-galactosidase (SA- $\beta$-gal) staining}

Cells were plated at a density of $4 \times 10^{4}$ cells in $35 \mathrm{~mm}$ culture dishes, washed with PBS and fixed with $3.7 \%(\mathrm{v} / \mathrm{v})$ paraformaldehyde in PBS for $3 \mathrm{~min}$ at room temperature. The presence of SA- $\beta$-gal activity was determined by incubating the cells with a solution containing $40 \mathrm{mM}$ citric acid-sodium phosphate $(\mathrm{pH}$ 6.0), $150 \mathrm{mM} \mathrm{NaCl}, 2 \mathrm{mM} \mathrm{MgCl}_{2}, 5 \mathrm{mM}$ potassium ferricyanide, $5 \mathrm{mM}$ potassium ferrocyanide and $1 \mathrm{mg}$ / $\mathrm{ml} \mathrm{X}$-gal for $17 \mathrm{~h}$ at $37^{\circ} \mathrm{C}$. The percentage of blue cells per 100 cells observed under a light microscope was measured.

\section{Total RNA extraction and reverse transcription- polymerase chain reaction}

RNAs were prepared from cells using the TRI solution according to the manufacturer's instructions. cDNA was prepared from RNA $(2 \mu \mathrm{g})$ using $2.5 \mu \mathrm{M}$ oligodT primers, $1 \mathrm{mM}$ dNTPs and moloney murine leukemia virus (MMLV) reverse transcriptase. XAF1, p53 and p16 were amplified from the cDNA with AccuPower ${ }^{\circledR}$ PCR PreMix (Bioneer Inc., Daejeon, Korea) and gene-specific oligonucleotides. GAPDH primers were used to estimate the amount of RNA in each sample. PCR products were separated on $1.2 \%$ agarose gels, and the DNAs were visualized by SYBR Green staining.

\section{Protein extraction and western blot analysis}

Cells were washed with PBS and lysed in $70 \mu \mathrm{l}$ of RIPA buffer (25 mM Tris-HCl, pH 7.6, 150 mM NaCl, 1\% Triton X-100, 0.5\% sodium deoxycholate, $0.1 \%$ SDS, 1 $\mathrm{mM}$ sodium vanadate, $5 \mathrm{mM} \mathrm{NaF}$ and protease inhibitor). The proteins were quantified with the bicinchoninic acid (BCA) method using bovine serum albumin as a standard. Proteins $(30 \mu \mathrm{g})$ were separated by $10 \%$ SDSpolyacrylamide gel electrophoresis and then transferred to nitrocellulose membranes. The membranes were incubated overnight at $4{ }^{\circ} \mathrm{C}$ with specific antibodies. After washing 5 times in Tris-buffered saline containing 1\% Tween 20 (TTBS), the membranes were incubated with horseradish peroxidase-conjugated secondary antibodies. The proteins were visualized using enhanced chemiluminescence (GE
Healthcare Life Sciences, Buckinghamshire, United Kingdom).

\section{Chromatin immunoprecipitation}

Cells $\left(1 \times 10^{6}\right)$ were plated on $100 \mathrm{~mm}$-culture plates and incubated under various conditions. Cells were treated with $1 \%$ formaldehyde for $10 \mathrm{~min}$ at room temperature to crosslink protein-DNA complexes. Cells were harvested, washed three times in $1 \times$ PBS and lysed in SDS with $50 \mathrm{mM}$ Tris-HCI (pH 8.1) and $1 \mathrm{mM}$ EDTA. Cells were sonicated for 1 hour, and the supernatants were evenly split for incubation with the primary antibodies. Reactions with a final volume of $1 \mathrm{ml}$ in dilution buffer with $2 \mu \mathrm{g}$ of the appropriate primary antibody were rotated overnight at $4^{\circ} \mathrm{C}$. Then, $60 \mu \mathrm{l}$ of Protein $\mathrm{A}$ beads was added to each reaction and rotated for $1 \mathrm{~h}$ at $4^{\circ} \mathrm{C}$. The beads were washed three times. The eluted supernatants as well as input DNA samples were then uncrosslinked via incubation at $65^{\circ} \mathrm{C}$ for $4 \mathrm{~h}$. The DNA was then ethanol precipitated and treated with Proteinase-K for $30 \mathrm{~min}$ at $37^{\circ} \mathrm{C}$. The samples were then extracted with phenol:chloroform, precipitated in ethanol and resuspended in $20 \mu \mathrm{l}$ of distilled water. Promoter binding activity was measured by real time-PCR analysis with specific promoter primers. The promoter primer sequences are as follows: (1) XAF1 promoter, (forward primer, 5'-cctgagtagctgggattata-3' and reverse primer, 5'-ctgggcagtctgtcaatatc-3') and (2) IRF1 promoter (forward primer, 5'-aatcccgctaagtgtttgga-3' and reverse primer, 5'-agtggaagagggaagaaggc-3').

\section{Flow cytometry}

Cells were harvested, washed twice with PBS and fixed with $70 \%$ ethanol at $-20^{\circ} \mathrm{C}$ for $1 \mathrm{~h}$. After washing the cells with PBS containing $2 \% \mathrm{FBS}$ and $0.01 \% \mathrm{CaCl}_{2}$, RNase $(0.5 \mu \mathrm{g} / \mathrm{ml})$ was added and incubated with the cells at $37^{\circ} \mathrm{C}$ for $30 \mathrm{~min}$. Then, propidium iodide $(50 \mu \mathrm{g} / \mathrm{ml})$ was added and incubated at room temperature for $20 \mathrm{~min}$. The intracellular propidium iodide fluorescence intensity of each population of 10,000 cells was measured using a Becton-Dickinson FACSCalibur flow cytometer.

\section{In vivo xenograft assay}

Nude mice (Balb/c, 5-week-old males) were obtained from Orientbio, Inc., (Seoul, South Korea) and maintained in a laminar air-flow cabinet under specific pathogen-free conditions. A549 cells were transduced with control shRNA virus (shCTR) or BRD7 shRNA virus (shBRD7) and a $0.1 \mathrm{ml}$ suspension of each containing $1 \mathrm{x}$ $10^{6}$ cells was subcutaneously injected into the right flank of each mouse. When the tumor size reached $150 \mathrm{~mm}^{3}$ for both the shCTR and shBRD7 groups, the mice treated with 
each shRNA were randomly divided into two groups (10 mice/group). The experimental group of mice received an intratumoral injection of vehicle or interferon- $\gamma$ (IFN- $\gamma$, $1 \times 10^{5}$ international units [IU]) solution three times a week. Two perpendicular diameters of the tumors were measured three times per week with a caliper square by the same investigator, and the tumor volume was calculated using the following equation: Tumor volume (V) $\mathrm{mm}^{3}=(\text { smaller diameter })^{2} \mathrm{x}$ (larger diameter) $\mathrm{x}(\pi / 6)$. The experiment was terminated 5 weeks after tumor cell implantation because the tumors in the control mice began to show signs of possible necrosis. The use of these animals and the experimental procedures were approved by the Institutional Animal Care and Use Committee of the Korea Institute of Radiological and Medical Sciences.

\section{Statistical analysis}

All of the data are presented as the mean \pm SD. Student's two-tailed $t$-test was employed for all of the analyses, and a $p$ value less than 0.05 was considered statistically significant.

\section{Abbreviations}

HMVEC, human pulmonary microvascular endothelial cell; XAF1, X-linked inhibitor of apoptosisassociating factor 1 ; BRD7, bromodomain 7 ; IFN- $\gamma$, Interferon-gamma; IRF-1, Interferon regulatory factor-1; $\mathrm{PD}$, population doublings; SA- $\beta$-gal, senescenceassociated $\beta$-galactosidase.

\section{ACKNOWLEDGMENTS}

This work was supported by the Basic Science Research Program (NRF-2013R1A1A2058621) and by the Nuclear Research and Development Program (NRF-2012M2A2A7012377) through the National Research Foundation (NRF), which is funded by the Ministry Science, ICT and Future Planning of the Korean government.

\section{CONFLICTS OF INTEREST}

The authors have no conflicts of interest to declare.

\section{REFERENCES}

1. Hayflick L and Moorhead PS. The serial cultivation of human diploid cell strains. Exp Cell Res. 1961; 25:585-621.

2. Lopez-Otin C, Blasco MA, Partridge L, Serrano M and Kroemer G. The hallmarks of aging. Cell. 2013; 153:11941217.

3. Bourgeron $\mathrm{T}, \mathrm{Xu} \mathrm{Z}$, Doumic $\mathrm{M}$ and Teresa Teixeira M. The asymmetry of telomere replication contributes to replicative senescence heterogeneity. Sci Rep. 2015; 5:15326.

4. Hanzelmann S, Beier F, Gusmao EG, Koch CM, Hummel S, Charapitsa I, Joussen S, Benes V, Brummendorf TH, Reid G, Costa IG and Wagner W. Replicative senescence is associated with nuclear reorganization and with DNA methylation at specific transcription factor binding sites. Clin Epigenetics. 2015; 7:19.

5. Serrano M, Lin AW, McCurrach ME, Beach D and Lowe $\mathrm{SW}$. Oncogenic ras provokes premature cell senescence associated with accumulation of p53 and p16INK4a. Cell. 1997; 88:593-602.

6. Jacobs JJ and de Lange T. Significant role for p16INK4a in p53-independent telomere-directed senescence. Curr Biol. 2004; 14:2302-2308.

7. Beausejour CM, Krtolica A, Galimi F, Narita M, Lowe SW, Yaswen P and Campisi J. Reversal of human cellular senescence: roles of the p53 and p16 pathways. EMBO J. $2003 ; 22: 4212-4222$.

8. Campisi J. Senescent cells, tumor suppression, and organismal aging: good citizens, bad neighbors. Cell. 2005; 120:513-522.

9. Peng C, Liu HY, Zhou M, Zhang LM, Li XL, Shen SR and Li GY. BRD7 suppresses the growth of Nasopharyngeal Carcinoma cells (HNE1) through negatively regulating beta-catenin and ERK pathways. Mol Cell Biochem. 2007; 303:141-149.

10. Kaeser MD, Aslanian A, Dong MQ, Yates JR, 3rd and Emerson BM. BRD7, a novel PBAF-specific SWI/SNF subunit, is required for target gene activation and repression in embryonic stem cells. J Biol Chem. 2008; 283:3225432263.

11. Drost J, Mantovani F, Tocco F, Elkon R, Comel A, Holstege H, Kerkhoven R, Jonkers J, Voorhoeve PM, Agami R and Del Sal G. BRD7 is a candidate tumour suppressor gene required for p53 function. Nat Cell Biol. 2010; 12:380-389.

12. Burrows AE, Smogorzewska A and Elledge SJ. Polybromoassociated BRG1-associated factor components BRD7 and $\mathrm{BAF} 180$ are critical regulators of $\mathrm{p} 53$ required for induction of replicative senescence. Proc Natl Acad Sci U S A. 2010; 107:14280-14285.

13. Dyson MH, Rose S and Mahadevan LC. Acetyllysinebinding and function of bromodomain-containing proteins in chromatin. Front Biosci. 2001; 6:D853-865.

14. Owen DJ, Ornaghi P, Yang JC, Lowe N, Evans PR, Ballario $\mathrm{P}$, Neuhaus D, Filetici P and Travers AA. The structural basis for the recognition of acetylated histone $\mathrm{H} 4$ by the bromodomain of histone acetyltransferase gen5p. EMBO J. 2000; 19:6141-6149.

15. Filetici $\mathrm{P}, \mathrm{P} \mathrm{O}$ and Ballario $\mathrm{P}$. The bromodomain: a chromatin browser? Front Biosci. 2001; 6:D866-876.

16. Horn PJ and Peterson CL. The bromodomain: a regulator of ATP-dependent chromatin remodeling? Front Biosci. 2001; 6:D1019-1023. 
17. Fong WG, Liston P, Rajcan-Separovic E, St Jean M, Craig $\mathrm{C}$ and Korneluk RG. Expression and genetic analysis of XIAP-associated factor 1 (XAF1) in cancer cell lines. Genomics. 2000; 70:113-122.

18. Liston P, Fong WG, Kelly NL, Toji S, Miyazaki T, Conte D, Tamai K, Craig CG, McBurney MW and Korneluk RG. Identification of XAF1 as an antagonist of XIAP antiCaspase activity. Nat Cell Biol. 2001; 3:128-133.

19. Xia Y, Novak R, Lewis J, Duckett CS and Phillips AC. Xaf1 can cooperate with TNFalpha in the induction of apoptosis, independently of interaction with XIAP. Mol Cell Biochem. 2006; 286:67-76.

20. Rodier F, Munoz DP, Teachenor R, Chu V, Le O, Bhaumik D, Coppe JP, Campeau E, Beausejour CM, Kim SH, Davalos AR and Campisi J. DNA-SCARS: distinct nuclear structures that sustain damage-induced senescence growth arrest and inflammatory cytokine secretion. J Cell Sci. 2011; 124:68-81.

21. Gentilini D, Mari D, Castaldi D, Remondini D, Ogliari G, Ostan R, Bucci L, Sirchia SM, Tabano S, Cavagnini F, Monti D, Franceschi C, Di Blasio AM, et al. Role of epigenetics in human aging and longevity: genome-wide DNA methylation profile in centenarians and centenarians' offspring. Age (Dordr). 2013; 35:1961-1973.

22. Ben-Porath I and Weinberg RA. The signals and pathways activating cellular senescence. Int J Biochem Cell Biol. 2005; 37:961-976.

23. Mantovani F, Drost J, Voorhoeve PM, Del Sal G and Agami R. Gene regulation and tumor suppression by the bromodomain-containing protein BRD7. Cell Cycle. 2010; 9:2777-2781.

24. Kim KS, Choi KJ and Bae S. Interferon-gamma enhances radiation-induced cell death via downregulation of Chk1. Cancer Biol Ther. 2012; 13:1018-1025.

25. Little MP. Risks associated with ionizing radiation. Br Med Bull. 2003; 68:259-275.

26. Garcia-Barros M, Paris F, Cordon-Cardo C, Lyden D, Rafii S, Haimovitz-Friedman A, Fuks Z and Kolesnick R. Tumor response to radiotherapy regulated by endothelial cell apoptosis. Science. 2003; 300:1155-1159.

27. Park HJ, Griffin RJ, Hui S, Levitt SH and Song CW. Radiation-induced vascular damage in tumors: implications of vascular damage in ablative hypofractionated radiotherapy (SBRT and SRS). Radiat Res. 2012; 177:311327.

28. Yentrapalli R, Azimzadeh O, Barjaktarovic Z, Sarioglu H, Wojcik A, Harms-Ringdahl M, Atkinson MJ, Haghdoost $\mathrm{S}$ and Tapio S. Quantitative proteomic analysis reveals induction of premature senescence in human umbilical vein endothelial cells exposed to chronic low-dose rate gamma radiation. Proteomics. 2013; 13:1096-1107.

29. Richardson B. Impact of aging on DNA methylation. Ageing Res Rev. 2003; 2:245-261.

30. Feser $\mathbf{J}$ and Tyler J. Chromatin structure as a mediator of aging. FEBS Lett. 2011; 585:2041-2048.

31. Grillari J and Grillari-Voglauer R. Novel modulators of senescence, aging, and longevity: Small non-coding RNAs enter the stage. Exp Gerontol. 2010; 45:302-311.

32. D'Aquila P, Rose G, Bellizzi D and Passarino G. Epigenetics and aging. Maturitas. 2013; 74:130-136.

33. McCord RA, Michishita E, Hong T, Berber E, Boxer LD, Kusumoto R, Guan S, Shi X, Gozani O, Burlingame AL, Bohr VA and Chua KF. SIRT6 stabilizes DNA-dependent protein kinase at chromatin for DNA double-strand break repair. Aging (Albany NY). 2009; 1:109-121.

34. O'Sullivan RJ, Kubicek S, Schreiber SL and Karlseder J. Reduced histone biosynthesis and chromatin changes arising from a damage signal at telomeres. Nat Struct Mol Biol. 2010; 17:1218-1225.

35. Narita M, Nunez S, Heard E, Lin AW, Hearn SA, Spector DL, Hannon GJ and Lowe SW. Rb-mediated heterochromatin formation and silencing of E2F target genes during cellular senescence. Cell. 2003; 113:703-716.

36. He J, Kallin EM, Tsukada Y and Zhang Y. The H3K36 demethylase $\mathrm{Jhdm} 1 \mathrm{~b} / \mathrm{Kdm} 2 \mathrm{~b}$ regulates cell proliferation and senescence through p15(Ink4b). Nat Struct Mol Biol. 2008; 15:1169-1175.

37. Franken NA, Rodermond HM, Stap J, Haveman J and van Bree C. Clonogenic assay of cells in vitro. Nat Protoc. 2006; 1:2315-2319. 